\title{
OM HJEMBLINDHED OG HUSETS ANTROPOLOGI
}

\author{
MAJA HØJER OG MARK VACHER
}

Antropologien er en videnskab, der legitimerer sig ved at indsamle data gennem feltarbejde. Dette har tit indbefattet ophold fjernt fra antropologens hjem i fjerne og fremmedartede sammenhænge. Antropologien er, kan man hævde, videnskaben om det eller måske rettere dem derude.

Og dog. Da Bronislaw Malinowski i 1922 udgav sin bog Argonauts of the Western Pacific, opsummerede han det vigtige ved sit ophold på Trobrianderne på følgende måde: „Det er ved at studere samfund som er os fjerne og fremmede, at vi kan kaste lys over vort eget" (Malinowski 1922:25).

Spørgsmålet er, hvorfor det hjemlige er så svært at begribe, at man må via omveje for at blive klogere på det. For Malinowski var svaret, at antropologiens „hjemme“ er for komplekst, og han rådede derfor sine studerende til at „holde sig til at lave rigtigt videnskabeligt arbejde i en uspoleret stamme" (Gutkind 1974:51).

Spørger man imidlertid Pierre Bourdieu, er det svære ved „hjemme“ ikke, at det er komplekst, men at det er hjemligt. Problemet er, hævder han, at „hjemme“ er kropsligt indlejret, så habituelt selvfølgeligt, at det sjældent springer i øjnene, og vi derfor næppe ænser det. Derfor, mener han, er vi nødsaget til at fremmedgøre det, objektivere det, trække det ud af kroppen og ind i sproget (Bourdieu 1980: 183).

Således må en antropologisk analyse af hjemmet nødvendigvis blive en analyse af noget andet, noget fremmed, hvorfra vi så forhåbentlig kan vende tilbage (Sjørslev 2007). Hjem som digterisk (og antropologisk) objekt er - som digteren Morten Søndergaard skriver det i sit digt i dette nummer - „et andet sted“.

Problemet er imidlertid, at antropologer i deres beskrivelser af ,de andre steder" har været tilbøjelige til at overse netop deres karakter af hjemlighed. Det og de fremmede er blevet beskrevet som slægtskaber, økonomier, kosmologier, produktions- og reproduktionsformer osv. med den konsekvens, at det overses, 
at det fjerne og fremmede er de fjerne og fremmedes hjem. På den måde er der tale om en dobbelt blindhed over for det hjemlige, som består i: 1) at vi glemmer, at vore objektiveringer igennem epistemologiske brud med praksis, jf. Bourdieu, river noget hjemmefra, og 2) at det, vi får øje på og studerer i det fremmede, i mange tilfælde er vigtigt for de fremmede, fordi det har hjemme der.

På den måde kan man hævde, at antropologer bør mindes om, at antropologien i lige så høj grad er en videnskab om at have hjemme. Eller som antropologen Michael Jackson formulerer det, en videnskab om, hvordan mennesker har hjemme i verden (Jackson 1995). Det at have hjemme er, som filosoffen Martin Heidegger har formuleret det, nært knyttet til det at bo. Det er at have sin plads, i ly og læ, et sted at komme fra og komme tilbage til, et sted at leve med andre, modtage andre eller være i fred for dem (Heidegger 2000:39).

At bo kommer imidlertid ikke af sig selv. Det er et forhold. Noget, man indgår i og manifesterer sig i. Dette er den stoflige dimension. Man afgrænser sin plads, værner sig ved at bygge, man opfører, flytter ind, domesticerer og tilpasser. At bo knytter sig til form og substans. Substansen - det vi kalder „,huset“ - varierer fra telte, huler, hytter, huse, lejligheder til husbåde. At bo knytter sig til materialitet, til ting i verden, som kan produceres, udveksles og gå til grunde. At bo knytter sig til værdi, hvad enten det er penge eller mere/andre moralske domæner.

Det er med denne holistiske, relationelle forståelse af at bo og have hjemme, at bidragyderne til dette tidsskriftsnummer har kastet sig over fænomenerne hus og hjem. Inden de enkelte bidrag præsenteres, er det imidlertid på sin plads at præsentere læserne for den faghistoriske kontekst.

\section{En oversigt over antropologi om huse, hjem og boliger}

I 1988 opfordrede Caroline Humphrey i et lille opråb i Anthropology Today til, at antropologer skulle beskæftige sig mere med boliger (dwellings) og det byggede miljø, så man kunne opnå en bedre forståelse af de forskellige sociale og kulturelle processer ved det at bo. Den foreteelse at have overset boliger kan skyldes, at når det først er lykkedes antropologen på feltarbejde at bosætte sig blandt folk og lære deres hverdag at kende, er huset og de hjemlige omgivelser blevet en selvfølgelig baggrund og kontekst for mere rituelle, abstrakte eller verbaliserede temaer som slægtskab, religion, politik eller økonomi (Hugh-Jones \& Carsten 1995:4). Men i virkeligheden er huset og hjemmet ankerpunkt og omdrejningspunkt for en lang række sociale processer, og det fortjener derfor i sig selv antropologisk opmærksomhed. Bourdieu beskriver husets rum som et „privilegeret sted“ til at forstå processerne i menneskers kropslige og begrebsmæssige tilegnelse af verden (Bourdieu 1977:89f.).

4 
Huset er imidlertid ikke kun et centralt sted, det er også en central tankefigur for menneskers sociale liv: Tænk bare på økonomi, der kommer af oikos (hus) og nomos (orden, lov, regler) og altså er tænkt ud fra husholdning og husets orden. Huset er en fundamental kategori i økonomi, slægtskabssystemer og politisk organisering i en lang række samfund (fx Elias 1983; Gudeman \& Rivera 1990; Kuper 1993; Wilson 1988).

Det er som dette knudepunkt, at Stephen Hugh-Jones og Janet Carsten satte huset $\mathrm{i}$ fokus med deres antologi About the House. Lévi-Strauss and Beyond $\mathrm{i}$ 1995. Husets antropologi skulle være en holistisk antropologi, der forbinder dele af livet som ellers betragtes adskilt. Den skulle kombinere klassiske modsætninger som offentlig/privat, profan/sakral, hverdagsliv/rituelt liv. Antologiens forfattere bygger videre på strukturalistiske analyser af huse - Lévi-Strauss' arbejde, selvfølgelig, og Bourdieus (2003 [1971]) klassiske beskrivelse af kabylerhuset som en spejling af samfundets orden ${ }^{1}-$ men fremhæver de dynamiske aspekter ved huse og bevægelserne på tværs af kategorier og modsætningspar. Som dette temanummers artikler viser, drejer livet i husene sig om transformationer og overskridelser, om både-og og sjældent enten-eller. Både natur og kultur, både produktion og forbrug, både ånd og substans (jf. Holston 1991).

Selvom Lévi-Strauss' teori om hussamfund som en særlig type samfund mellem slægtskabsbaserede samfund og klassesamfund ikke kunne modstå den empiriske mangfoldighed, der findes i relationen mellem huse og de mennesker og grupper, der bebor dem, så lykkedes det antologiens forfattere at bidrage til opbygningen af en husets antropologi, som kombinerer det materielle med det immaterielle og det sociale. Ligesom personer er huse dynamiske enheder, som fødes, modnes, bliver gamle og dør/opløses. Der er altså nogle paralleller mellem huse og personer, som vi kender fra mange sammenhænge: Børn tegner huse som personer med vinduer som øjne og døre som næser. Vi fortæller gerne om huses ,personlighed“ og „livshistorier“ og ser sammenhænge mellem et hus' stabilitet og en persons integritet. Ligesom mennesker har huse en alder, en forside og en bagside - og nogle skyggesider.

Gennem godt det sidste årti har der været en stigende antropologisk opmærksomhed på „hjem“ (Chapman \& Hockey 1999; Cieraad 1999; Birdwell-Pheasant \& Lawrence-Zúñiga 1999; Miller 2001). Nogle af disse studier er fra Europa og Nordamerika og ofte fra antropologens eget hjemland, fx Cieraad (1999), Birdwell-Pheasant og Lawrence-Zúñiga (1999) og Miller (2001). Den norske antropolog Marianne Gullestad, som døde alt for tidligt i marts 2008, lagde en vigtig grundsten i studiet af huse og hjem med sit feltarbejde blandt arbejderklassekvinder i Bergen $(1984,1989)$. Siden har flere antropologiske og etnologiske studier i Norden omhandlet hjemlighed (Winther 2006) og hjemmet som central 
institution og kulturel kategori, både i forhold til kosmologi (Gullestad 1992a), køn (Gullestad 1992b) og klasse (Gullestad 1984; Löfgren 2003). Til denne regionale etnografi om hjemmets betydning tilføjer artiklerne i dette temanummer flere væsentlige dimensioner: Person og identitet (Kofod), slægtskab og moralske relationer (Sjørslev; Tjørnhøj-Thomsen), tid og tidsopfattelser (Vacher) og velfærdsstatens institutioner og ideologi (Højlund).

Interessen i hjemmet kommer fra og går i flere retninger: Flere af bidragene i Cieraads (1999) og Birdwell-Pheasant og Lawrence-Zúñigas (1999) antologier analyserer det sociale liv og strukturer i hjemmet ud fra hjemmets arkitektur og indretning eller beskriver den historiske konstruktion af det hjemlige. Begge antologier kombinerer antropologi, socialhistorie og arkitektur.

Millers antologi (2001) tager udgangspunkt i hjemmets materielle kultur. Efter de strukturalistiske analyser af huses og samfunds kosmologi og orden (se ovenfor) var der i 1980'erne fokus på forbrug og på, hvordan folk (i hjemmet og andre steder) udtrykte deres identitet gennem forbrug og indretning. Bidragene i Home Possessions (2001) tager igen en ny retning: I stedet for at se på folks indretning og (for)brug af ting som et udtryksmiddel undersøger de, hvordan hjemmet og tingene i hjemmene virker tilbage på beboerne, og hvad hjemmenes materialitet gør ved dem. Med andre ord er det ikke kun os, der ejer og styrer vores hjem og vores ting, men også til en vis grad tingene og hjemmet, der ,ejer“ og styrer os, på utilsigtede måder.

Både sociologer (Allan \& Crow 1989), geografer (Blunt \& Dowling 2006) og et fag som ,environmental psychology“ (Moore 2000) studerer hjemmets betydning i ,moderne samfund“". Af andre tilgange til hjem kan nævnes den socialpsykologiske tilgang (fx Csikszentmihalyi \& Rochberg-Halton 1981; Marcus 1995). Gennem udvekslingen mellem mennesker og genstande i hjemmet formuleres person, selv og identitet. Hjem er det sted, hvor man „er sig selv“ eller „finder sig selv“, hører man ofte. Csikszentmihalyi og Rochberg-Halton (1981) er blevet et klassisk værk, også for antropologer. I deres symbolske analyse af amerikaneres forhold til deres hjem beskriver de hjemmet som det mest magtfulde tegn på selvet (op.cit.123).

Ideen om hjem gør sig gældende andre steder end i boliger, blandt andet i politisk-symbolske tilgange til nation og hjem (fx George 1996; Holy 1998), ligesom forskellige betydninger af hjem er blevet diskuteret i studier af migration og migranters identitet (fx Ahmed et al. 2003; Ambruster 2002; Malkki 1992; Olwig 1997, 1998; Rapport \& Dawson 1998). ${ }^{2}$

Det er ikke første gang, Tidsskriftet Antropologi beskæftiger sig med huse og hjem. I forbindelse med symposiet „Hjemfølelse“ (Westman 1989) og udgivelsen af bogen In Defence of Homesickness: Nine Essays on Identity and Locality 
(Schwartz 1989) udspandt der sig en levende debat i tidsskriftets spalter om begreber som hjem, hjemve, hjemfølelse og hjemstavn. Dyk ned i de gamle numre og læs dialogen mellem Arno Victor Nielsen og Schwartz om Heideggers poetik vedrørende Heimat i nr. 17 (1988), læs Michael Harbsmeiers anmeldelse af Schwartz' bog i nr. 19 (1989) og Schwartz' svar til ham i nr. 20 (1990) eller nr. 28 om migration (1993), hvor Schwartz' skriver om „Hjem igen“ under rubrikken Position.

\section{Substans og ånd}

Dette nummer indeholder otte artikler og fem enqueter. Enqueterne repræsenterer forskellige, anderledes greb på huse og hjem. Enqueterne skal bryde tidsskriftets rytme og invitere læseren til at dykke ned i helt andre verdener - kunstneriske, litterære, historiske og teologiske - til inspiration, refleksion og fornøjelse. I det følgende præsenterer vi artikler og enqueter.

Sjørslevs og Raahauges artikler behandler på hver sin måde forholdet mellem det materielle og immaterielle ved hjem. Begge når bag om den rationalitet, som moderne hjem ved første øjekast er organiseret efter.

Ved at snakke med folk om spøgelser og hjemsøgelser og optegne deres historier om knirkende gulve, blålig-transparente spøgelser og andre ,irrationelle“ sansefænomener har Raahauge nærmet sig den ,irrationelle“, tabubelagte usikkerhed, flertydighed og ontologiske ustabilitet, som er en side af hjemmet, der normalt ikke italesættes. Hjem står normalt for nærvær og stabilitet, men hjemsøgelser artikulerer det konstant truende fraveer i nærværet og den truende destabiliseringen af hjemmet. Hjemmet kan være varmt og venligt, men det kan også være tyranniserende og voldeligt i sin disciplinering af beboerne (Douglas 1991; Olwig 1998).

Spøgelser og hjemsøgelser peger på ,hjemmets ustabile skyggesider, på uhyggen i hyggen", som er en del af hjemmets fænomenologi. For den, der ser et spøgelse, reprcesenterer spøgelset ikke det uhyggelige, men det er uhyggeligt. Det reprcesenterer ikke tab af kontrol, men er et tab af kontrol. Uhyggens væsen er en erfaring, som Freud med sit begreb „das Unheimliche“ fortolker, giver betydning og begrunder, men som i sin væren er ét med det „heimliche“/hjemlige. Spøgelset påviser en radikal essens ved hjemmet, som ikke er til at begribe, men som alligevel er der - og i næste øjeblik så alligevel ikke. Med hjemsøgelser har Raahauge fundet en begrebsverden og et sprog, som lægger vigtige dimensioner til forståelsen og beskrivelsen af hjemmets verden og hjemmets væsen.

Sjørslev udfordrer økonomiske „rationelle“ forestillinger om huse som investeringer: Selvom parcelhuse er familiers største økonomiske aktiv og en af- 
gørende økonomisk binding, så ,investerer“ husejere i lige så høj grad i sociale relationer, i deres børns opvækst i grønne områder og i rammen om familiens samliv. Den dag husets værdi belånes, kan det ske som investering i børnenes uddannelse eller for at komme andre til hjælp. Ud fra dette perspektiv er ,friværdi“ ikke „fri“, men altid spundet ind i sociale relationer. Forbruget i og omkring husene er forbundet med samvær, forpligtelser og moralske bindinger. Kort sagt med en slags kald. Det er ikke kun sådan, at hjemmet og familien lukker sig om sig selv, og at forbrugets moral kun angår privatlivet, den er i vekselvirkning med og et billede på samfundets herskende moral. Dette viser Sjørslev gennem en overbevisende og ,autoetnografisk“ fortælling om sin egen og sin egen generations opvækst i og siden flugt fra forstædernes parcelhuskvarterer i 50'erne og 60 'erne og videre frem.

Parcelhuses værdier er lige dele kald og drømmestof. I parcelhusets verden eksisterer både nutid og fremtid, dagens dont og potentialet til fest og ritualer. Den er en materialisering af sociale relationer og en socialisering af det materielle. Begge artikler peger på hjemmets flertydige rolle, der gør det muligt at samle substans og ånd og det materielle og det sociale.

\section{Hjem uden børn, børn uden hjem}

Hjem er konstitueret gennem relationer, både gennem relationerne mellem de mennesker, der bebor dem, og gennem relationerne mellem menneskene og boligens bebyggelse og genstande. Det bevidner Tjørnhøj-Thomsens artikel om barnløses kobling af huskøb, boligindretning og forældreskab og Højlunds artikel om anbragte børn i hjemlignende institutioner i højeste grad. Til et rigtigt hjem hører børn, og børn har brug for et rigtigt hjem, tilskriver forestillingerne om det gode og sunde liv i Danmark - hvilket bliver særligt tydeligt under fravær af netop børn eller hjem.

Tjørnhøj-Thomsen bringer de materielle dimensioner ved familieliv og slægtskab frem gennem barnløse pars tanker om huse og deres indretning. Par med ønske om at få børn og stifte familie køber eller bygger hus og indretter sig, i takt med den familieforøgelse de forventer - og omvendt holder de igen, hvis de forventede børn ikke kommer. Genstande i og omkring hjemmet vidner om de personer, der skal bo i hjemmet eller har boet der. Forholdet mellem hjem og person er både meget intimt, privat og inderligt og samtidig socialt, idet genstandene så at sige indeholder de personer, som har foræret dem eller anskaffet dem.

Højlunds artikel om de såkaldte miniinstitutioner for anbragte børn, som tilstræber ,at skabe små, overskuelige, hjemlignende institutioner“, beskæftiger sig med relationen mellem hjem, autenticitet og velfærdsstatens institutioner. Både 
børn og ansatte i miniinstitutionerne giver udtryk for de paradokser, der er forbundet med, at døgninstitutioner for anbragte børn skal efterligne hjem: Pædagogerne er bevidste om, at de skal skabe et autentisk „,normalt“ dansk hjem for børnene og ikke være for ,institutionsagtige“. „Et autentisk hjem“ er et stærkt symbol i miniinstitutionernes ideologi om et godt liv. Pædagogerne skal dog samtidig være „professionelle“ og må ikke opføre sig som i deres private hjem. Børnene søger autentiske relationer til pædagoger, som ikke bare er ,på arbejde“, og giver derved udtryk for, at hjem er en kvalitet ved relationerne i hjemmet, som i sig selv står i modsætning til institutionen. På den måde viser Højlund, at forestillinger om hjem gennemtrænger og transformerer et skel mellem offentligt og privat, som miniinstitutionerne både opretholder og nedbryder.

Begge artikler demonstrerer og problematiserer sammenhængen mellem materialitet og socialitet: Tjørnhøj-Thomsen lægger en tidslig og moralsk dimension til forholdet mellem socialitet og materialitet gennem parrenes frygt for nemesis, at børnene slet ikke kommer, hvis man bygger deres værelser færdige for tidligt eller flytter barnevogne ind i huset. Det kan være farligt at knytte håb for fremtiden alt for tæt til materielle genstande, mens minder fra fortiden mere uproblematisk lagres i hjemmets ting. At dette ikke altid er tilfældet demonstrerer Raahauges spøgelseshistorier imidlertid. Hos Højlund er det kravet om autenticitet, som problematiserer det forhold, at hjemmet udgøres af relationer mellem mennesker og ting og mennesker indbyrdes. Det er ikke kun bestemte ting og bestemte handlinger (stearinlys, højtlæsning og hygge), som udgør hjemmet. Det skal være på en bestemt måde, og relationerne skal være af en særlig kvalitet.

Både Tjørnhøj-Thomsen og Højlund inddrager historiske diskurser om, hvordan ideen om familiens hjem og børnehjem er opstået. I „Bondestuen - et hjem i svøb" beskriver Rønne bondestuen som en tidlig form for hjem i Danmark, før ,hjem“" med industrialiseringen blev et begreb og et sted, man forlod og derfor kunne tale og fortælle om. Bondestuen rekonstrueres på afstand, gennem etnologiske og historiske beskrivelser, erindringer, livshistorier og guldaldermalerier. På den måde virker bondestuen som en model af og model for hjem, da den er blevet en prototype på hjem gennem den måde, den erindres på.

I sognepræst og forfatter Erik Dybdal Møllers enquete beskrives hjem og hjemlængsel i dansk kristen tradition. Længe før hjemmet refererede til jordiske hjem, som mennesker selv skabte, trådte forestillingen om et himmelsk hjem hos Gud og nærværet i Guds hus frem i Biblen og kristne salmer. Her findes hjemmet både som længslen efter et hinsides hjem og som en dennesides gave, der skal forvaltes gennem dagliglivets arbejde, en mark eller jordlod, der skal dyrkes. Både hjemlængsel og kald er altså kendt fra det religiøse liv, før nostalgi også kunne rettes mod verdslige hjem. 


\section{Når hjem går til grunde}

Hjemmet er for mange mennesker det mest solide referencepunkt i livet. Det kan, som Frida Hastrups og Jens Kofods bidrag på forskellig måde viser, udgøre et ontologisk fundament, som, hvis det bryder sammen, risikerer at ryste tilværelsen til ukendelighed.

I december 2004 ramte og oversvømmede en voldsom flodbølge store kystområder i Sydøstasien. Med udgangspunkt i sit feltarbejde i den indiske by Tharangambadi analyserer Frida Hastrup lokale fiskeres kamp for at finde hjem og genetablere tilværelsen i et landskab, der er smadret af vandmasserne, og hvor familiemedlemmer og venner er druknet. Samtidig er det det selv samme landskab, som sikrer fiskerne deres eksistensgrundlag. Det er på stranden, fiskene landes, sorteres og renses, og det er her, nettene og bådene repareres og opbevares. Før tsunamien boede fiskerne nær stranden, og hjem og arbejde var nært forbundet, men efter 2004 er der takket være nødhjælp blevet opført nye boliger i sikker afstand fra havet.

Problemet med disse huse er imidlertid, at de ikke på samme måde som et hus på stranden kan glide ind i og understøtte forestillinger om en fremtid som fisker. Resultatet er, viser Hastrup, at de sikre huse opfattes ikke blot som fremmedgørende, men også som skyggende for udsigten til og håbet om at genetablere en tilværelse som før tsunamien. Dette har fået nogle af fiskerfamilierne til at bosætte sig på stranden, fordi denne, på trods af at have været et katastrofalt og livsfarligt sted, ikke desto mindre er bedre egnet som fundament for et hjem og en tilværelse.

Jens Kofods artikel beskæftiger sig også med ændringer, som underminerer hjemmets status som ontologisk grundpille. Her kommer ændringerne imidlertid ikke udefra, men indefra, når kroppen mister evnen til at holde hus og hjem. På baggrund af et feltarbejde blandt ældre danskere beskriver og analyserer han processen fra at bo i eget hjem, til de ældre er flyttet på plejehjem. Kofod betegner denne proces som afvikling af hjem. Afviklingen, viser han, begynder allerede i de ældres hjem, i og med at de, når kroppen svækkes, i stigende grad bliver afhængige af pleje og anden hjælp. Konsekvensen er, at de ældre, i takt med at de mister førligheden, også mister hjemligheden, idet mængden af fremmede, som har adgang til boligen, ikke blot stiger, men kontrollen med disse og deres aktiviteter også glider de ældre af hænde. Således, hævder Kofod, sker der parallelt en opløsning af hjem og person, idet den ældre fra at være agerende subjekt glider mod at være en krop, et objekt, der skal håndteres og behandles.

Hvad angår hjemmets opløsning, bliver denne proces synlig i håndteringen af de ældres ejendele. For de flestes vedkommende betyder flytningen til plejehjem en reduktion af plads. Dette medfører, at de ældres ejendele må sorteres og 
reduceres. I den proces ændrer ejendelene karakter, idet de fra at indgå i en helhed enten medbringes på plejehjemmet, som minder om en tidligere tilværelse, gives bort til pårørende eller kasseres. I mange tilfælde foretages denne sortering ikke af de ældre selv, men af pårørende, hvilket bidrager til det, der betegnes som personens opløsning.

Fælles for ovennævnte bidrag er, at de illustrerer og understreger hjem som konstituerende for person og tilværelse. Når huse ødelægges og forfalder, er det ofte meget mere end ejendom, der går tabt. Det er, hvad fænomenologisk betegnes som en livsverden (Ingold 2000; Jackson 1995).

Mens ovennævnte bidrag behandler huse og kroppe som udsatte fysiske fundamenter, er hjemmets sammenbrud i Gerd von Buchwald Lütkens enquete af en mere ideologisk karakter. Med eksempler fra Kafka, Rilke og Benjamin vises det, hvordan disse forfattere fremstiller hjemmet, familien og moderen som så udhulede, at de ikke længere kan fungere som ontologiske fundamenter. Resultatet i de citerede værker er død, ensomhed og selvmord samt en overvældende meningsløshed, der (mest tydeligt hos Walter Benjamin) undergraver ikke blot forfatternes nutid og håb for fremtiden, men også alt, hvad der har været af godt og rigtigt.

Med dette tab af livsverden tabes også respekten for menneskelivet som noget sublimt og det sociale som et moralsk og følelsesmæssigt sikkerhedsnet. Således, hævdes det, er det netop forfattere som Kafka, Rilke og Benjamin, der i deres fremstilling af hjemmet med kunstnerisk forudseenhed først og tydeligst blotlægger, hvad der få år senere kulminerer i Første Verdenskrigs barbari.

\section{Hjem til naturen}

I 1992 beskrev den norske antropolog Marianne Gullestad hjemmet som udgørende et inde i modsætning til et $u d e$ (Gullestad 1992a:201). Til ude hører blandt andet naturen, som kan være både utæmmet og vild. Denne sondring mellem hjem og natur, som blandt andet er et gennemgående tema i mange europæiske eventyr (Grimm 1998), er både praktisk og genkendelig de fleste steder i verden, men som Skrædderdal Jakobsens bidrag viser, udgør den ikke i sig selv en definition på hus, hjemlighed eller for den sags skyld naturen.

Med udgangspunkt i et feltarbejde gennemført blandt homesteaders i Oregon analyserer hun en gruppe menneskers mangeårige forsøg på at „vende hjem til naturen“. Deres ambition er, som det forklares, at „opgive rollen som „kultivatorer“ af naturen og fouragere ligesom de øvrige væsner, der har hjemme i skoven“.

Det paradoksale er imidlertid, at opgivelsen af rollen som „kultivatorer“ afføder en refleksiv praksis, som ikke forekommer hos de andre væsner i skoven. 
Gennem cases vises det, hvordan naturen i form af blandt andet æstetik og rotter tvinger homesteaderne til at forholde sig til arkitektur og formgivning samt etablering af domæner for ,menneskehabitation“. Dels indføres kosmologiske symboler som yin og yang i udformningen af byggeri for at undgå, at huset kommer til at være „en stor kasse“, og dels forvises rotterne fra køkkenet gennem meditation, rengøring og i sidste ende fælder og gift.

Således er vejen til at opfylde ambitionen om at finde hjem til naturen belagt med en uendelig række af forhandlinger af de kategorier, som homesteaderne forsøger at opløse.

Mens homesteadernes bestræbelser på at finde hjem har en stærkt refleksiv og kosmologisk karakter, behandler Bror Westman i sin enquete en mere eksplorativ tilgang til at skabe hjem i naturen. Det handler om børns huler i omegnen af Kokkedal. I enqueten typologiseres hulerne i forhold til parametre som køn, alder og byggestil, og der gives eksempler på, hvorledes forhåndenværende materialer inddrages i domesticeringen af et sted i skoven/skovbrynet og konstruktionen af et særligt sted.

At konstruere særlige steder i naturen tilfalder imidlertid ikke kun homesteadere og børn. I sin artikel behandler Vacher noget, der ved første øjekast fremstår som modsætningen til homesteadernes opfattelse af at bo i naturen, nemlig beboelse i danske sommerhusområder. Siden 1999 har det været lovligt for danske pensionister at bo hele året i deres sommerhuse. Gennem cases undersøges transformationen fra feriebolig til helårsbolig. Fra i bogstavelig forstand at udgøre panoramavinduer til naturen vendes sommerhusene så at sige indad, når de bliver til helårshuse. Dette gælder såvel arkitektonisk som socialt. Hvad angår form, kendetegnes sommerhuse ved store udearealer, $\mathrm{fx}$ i form af terrasser, der gerne vender ud mod havet eller skoven. Endvidere har mange sommerhuse store vinduespartier, som ofte kan åbnes, hvorved naturen i form af lys, vind, duft og lyd inviteres indenfor. Som helårshuse er det typisk disse arealer, der overbygges og inkluderes i huset som udvidelser af køkkener og opholdsrum. I forhold til det sociale sker en lignende proces. I sommerhusene opholder man sig meget ude, går ture og lader sig ,ruske og blæse igennem“, og har man besøg, er samværet uformelt, ligesom man gerne deles om opvasken. Når sommerhuset bliver helårsbolig, ændres også dette. Er vejret dårligt, bliver man inden døre, og får man gæster, forventes disse at respektere private domæner i huset, mens de til gengæld kan forvente at blive beværtet uden at skulle deltage i rengøring eller opvask.

Hvad de tre bidrag på forskellig vis understreger, er en grundlæggende antropologisk pointe, nemlig at det er måden, vi lever og bor på, som afgør, hvordan vi former og bygger (Ingold 2000:188). 


\section{Hus og hjem}

Som afslutning på denne introduktion til temanummeret „Hus og hjem“ er det passende at komme med en opfordring til læseren: Det er vort håb, at læseren gennem de forskellige artikler og enqueters fremstillinger af andres hjem holder sit eget i erindring, lader det spejle sig og sammenligne. Dels vil en sådan refleksion bringe berigende antropologi med hjem fra Indien, Oregon, børnehjemmet, plejehjemmet, spøgelsernes huse og parcel- og sommerhusene, og dels vil læseren efter endt læsning kunne vende (sig) klogere hjem til den sammenhæng, som Malinowski fandt alt for kompleks til at kunne begribes gennem „real scientific work" (Gutkind 1974:51).

God fornøjelse.

\section{Noter}

1. På dansk har vi Bror Westmans „Manden, kvinden, huset. Fra et feltarbejde i Nordafrika“ (Westman 1989).

2. Henvisningerne i denne oversigt er ikke fyldestgørende, men tænkt som en inspiration og nogle bud på, hvor man kan starte en videre udforskning.

\section{Litteratur}

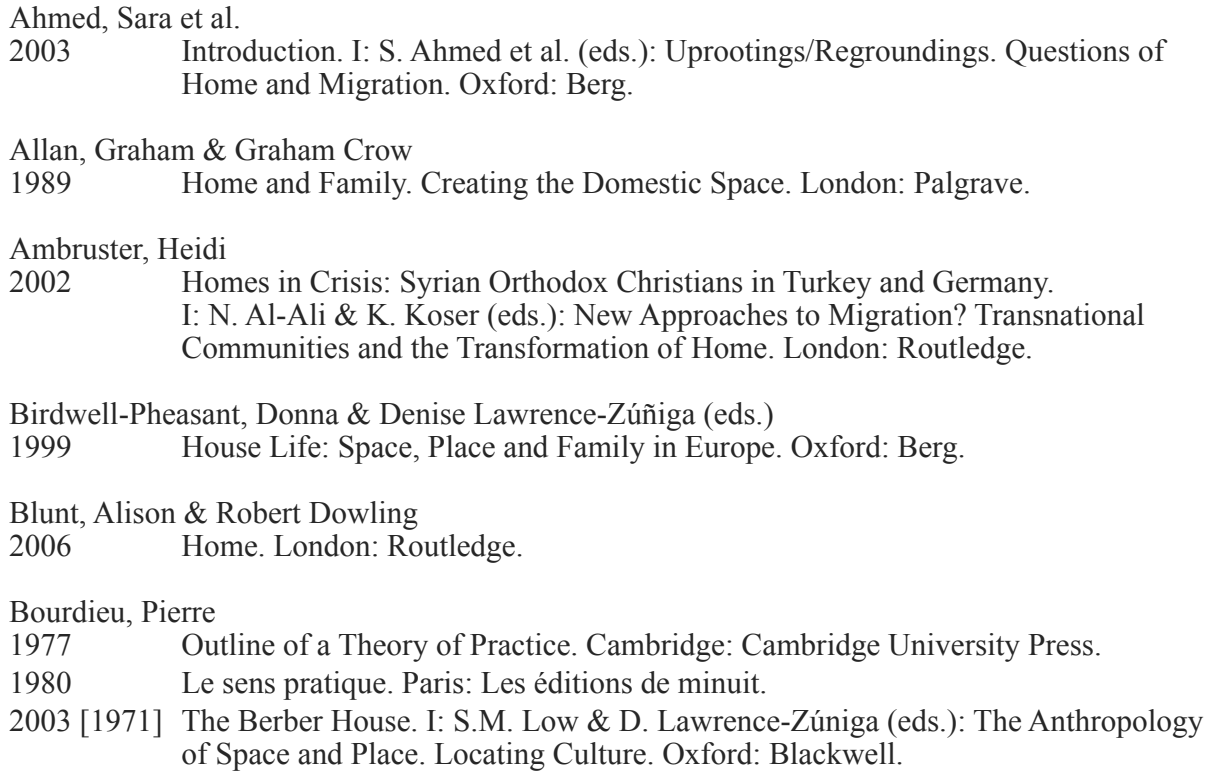


Chapman, Tony \& Jenny Hockey (eds.)

1999 Ideal Homes? Social Change and Domestic Life. London \& New York: Routledge.

Cieraad, Irene (ed.)

1999 At Home. Space, Place, and Society. Syracuse, NY: Syracuse University Press.

Csikszentmihalyi, Mihaly \& Eugene Rochberg-Halton

1981 The Meaning of Things. Domestic Symbols and the Self. Cambridge: Cambridge University Press.

Douglas, Mary

1991 The Idea of a Home: A Kind of Space. Social Research 58(1):287-307.

Elias, Norbert

1983 The Structure of Dwelling as an Indicator of Social Structure. I: N. Elias: The Court Society. Oxford: Blackwell.

George, Rosemary Marangoly

1996 The Politics of Home: Oostcolonial Relocations and Twentieth Century Fiction. Cambridge: Cambridge University Press

Grimm, Jacob \& Wilhelm Grimm

$1998 \quad$ Grimms eventyr. Holte: Forlaget Flachs.

Gudeman, Stephen \& Alberto Rivera

1990 Conversations in Colombia. The Domestic Economy in Life and Text. Cambridge: Cambridge University Press.

Gullestad, Marianne

1984 Kitchen-Table Society. A Case-Study of the Family Life and Friendships of Young Working-Class Mothers in Urban Norway. Oslo: Universitetsforlaget.

1989 Kultur og hverdagsliv. Oslo: Universitetsforlaget.

1992a When Nature is More Important Than Culture. I: M. Gullestad (ed.): The Art of Social Relations. Essays on Culture, Social Action and Everyday Life in Modern Norway. Oslo: Scandinavian University Press.

1992b Home Decorations as Popular Culture. I: T. De Valle (ed.): Gendered Anthropology. London: Routledge.

Gutkind, Peter C.V.

1974 Urban Anthropology. Assen: Van Gorcum.

Harbsmeier, Michael

1989 Hjemve. Tidsskriftet Antropologi 19:91-103.

Heidegger, Martin

$2000 \quad$ Sproget og ordet. København: Hans Reitzels Forlag.

Holston, James

1991 Autoconstruction in Working-Class Brazil. Cultural Anthropology 6(4):447-65.

Holy, Ladislav

1998 The Metaphor of 'Home' in Czech Nationalist Discourse. I: N. Rapport \&

A. Dawson (eds.): Migrants of Identity: Perception of Home in a World of

Movement. Oxford: Berg.

Humphrey, Caroline

1988 No Place Like Home in Anthropology. Anthropology Today 4(1):16-18.

14 
Ingold, Tim

2000 The Perception of the Environment. Essays on Livelihood, Dwelling and Skill.

Jackson, Michael

London \& New York: Routledge.

1995 At Home in the World. Durham: Duke University Press.

Kuper, Adam

1998 The 'House' and Zulu Political Structure in the Nineteenth Century. Journal of African History 34(3):469-87.

Löfgren, Orvar

2003 [1984] The Sweetness of Home: Class, Culture and Family Life in Sweden. I: S.M. Low \& D. Lawrence-Zúñiga (eds.): The Anthropology of Space and Place. Locating Culture. Oxford: Berg.

Malinowski, Bronislaw

1922 Argonauts of the Western Pacific. London: Routledge and Kegan Paul.

Malkki, Liisa

1992 National Geographic: The Rooting of Peoples and the Territorialization of National Identity among Scolars and Refugees. Cultural Anthropology 7(1)

Marcus, Clare Cooper

1995 House as a Mirror of Self. Exploring the Deeper Meaning of Home. Berkeley: Conari Press.

Miller, Daniel (ed.)

$2001 \quad$ Home Possesions. Oxford: Berg.

Moore, Jeanne

2000 Placing Home in Context. Journal of Environmetal Psychology 20(3):207-17.

Nielsen, Arno Victor

1987/88 Nomadetænkning. Tidsskriftet Antropologi 16:129-46.

Olwig, Karen Fog

1997 Culture Sites: Sustaining a Home in a Deterritorialized World. I: K.F. Olwig \& K. Hastrup (eds.): Siting Culture: The Shifting Anthropological Object. London: Routledge Mental Health.

1998 Contesting Homes: Home-Making and the Making of Anthropology. I: N. Rapport \& A. Dawson (eds.): Migrants of Identity: Perceptions of Home in a World in Movement. Oxford: Berg.

Rapport, Nigel \& Andrew Dawson

1998 Home and Movement: A Polemic. I: N. Rapport \& A. Dawson (eds.): Migrants of Identity. Perceptions of Home in a World of Movement. Oxford \& New York: Berg.

Schwartz, Jonathan

1988 Er Heidegger en nomade eller en husmand? Et svar til Arno Victor Nielsen. Tidsskriftet Antropologi 17:165-7.

1989 In Defence of Homesickness: Nine Essays on Identity and Locality. København: Akademisk Forlag.

$1990 \quad$ Kære Michael. Tidsskriftet Antropologi 20:117-9.

1993 Hjem igen. Tidsskriftet Antropologi 28:151-4. 
Sjørslev, Inger

2007 Husets univers. Om danske enfamiliehuse i tid og rum. Dansk Sociologi 4(18): $107-22$.

Westman, Bror

1989 Manden, kvinden, huset. Fra et feltarbejde i Nordafrika. I: K. Hastrup \&

K. Ramløv (eds.): Kulturanalyse. Fortolkningens forløb i antropologien.

København: Akademisk Forlag.

Wilson, Peter J.

1988 The Domestication of the Human Species. New Haven: Yale University Press.

Winther, Ida Wentzel

2006 Hjemlighed. Kulturfænomenologiske studier. København: Danmarks Pædagogiske Universitets Forlag. 